\title{
INDICADORES DE DESIGUALDADE DE GÊNERO NO BRASIL
}

\author{
José Eustáquio Diniz Alves ${ }^{1}$ \\ e Suzana Marta Cavenaghi ${ }^{2}$
}

\begin{abstract}
RESUMO
As mulheres brasileiras conquistaram diversas vitórias parciais no século XX: obtiveram 0 direito de voto, em 1932, mas não conseguiram ultrapassar o teto de 10\% de deputadas federais; conquistaram graus crescentes de educação em todos os níveis de ensino, mas ainda estão pouco representadas nas ciências exatas e na liderança dos grupos de pesquisa; aumentaram as taxas de participação no mercado de trabalho, mas ainda sofrem com a segregação ocupacional, a discriminação salarial, além da dupla jornada de trabalho; conquistaram diversas vitórias na legislação nacional, mas, na prática, ainda são vítimas de discriminações e preconceitos. Em termos de esperança de vida elas vivem, em média, sete anos acima da média masculina e são maioria da população e do eleitorado. Elas conseguiram reduzir diversas desigualdades de gênero e reverter outras. Contudo, mesmo tendo uma mulher na Presidência da República, ainda falta muito para o Brasil chegar a uma justa equidade de gênero.
\end{abstract}

Palavras-chave: Desigualdade de gênero. Empoderamento das mulheres. Indicadores sociais. Brasil.

\footnotetext{
${ }^{1}$ Pesquisador Doutor da Escola Nacional de Ciências Estatísticas (ENCE) do Instituto Brasileiro de Geografía e Estatistica (IBGE), Brasil. jed_alves@yahoo.com.br

${ }^{2}$ Pesquisadora Doutora da Escola Nacional de Ciências Estatísticas (ENCE) do Instituto Brasileiro de Geografía e Estatistica (IBGE), Brasil. suzana_cavenaghi@uol.com.br
} 


\title{
INDICATORS OF GENDER INEQUALITY IN BRAZIL
}

\begin{abstract}
Brazilian women achieved many partial victories in the twentieth century: they obtained the right to vote in 1932, but they were not able to surpass the prevailing existing $10 \%$ women participation in congress; they advanced in all levels of education, but they are still underrepresented in exact sciences and in research groups leadership; they increased participation rates in the labor market, but they still face occupational segregation, salary discrimination, and double working day; they achieved several victories in national legislation, but they are still victims of prejudice and discrimination. In terms of life expectancy, they live an average of seven years longer than men, and they are also the majority of population and electorate. They were able to reduce many gender inequalities and reverse others. However, despite having a woman as President, Brazil has still a long way to go to reach gender equity.
\end{abstract}

Keywords: Gender inequality. Women empowerment. Social indicators. Brazil.

\section{AS DESIGUALDADES DE GÊNERO}

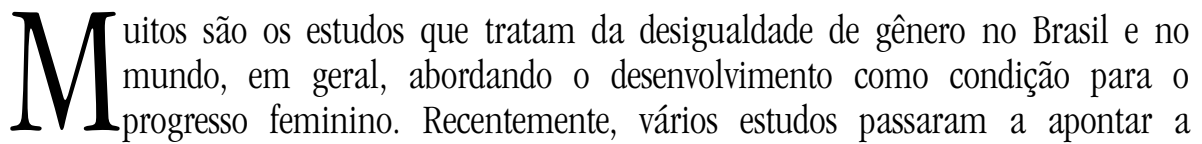
importância da autonomia feminina para o desenvolvimento. Para Esther Duflo (2011, p. 2), o empoderamento das mulheres está positivamente relacionado com 0 desenvolvimento econômico, sendo que um fenômeno reforça o outro: "em um sentido, o desenvolvimento joga um papel importante na diminuição da desigualdade entre homens e mulheres, em outra direção, o empoderamento das mulheres pode beneficiar o desenvolvimento".

Mas existem também estudos tratando, além do empoderamento das mulheres, das desigualdades reversas de gênero (ALVES; CORREA, 2009; GOLDIN, 2006). Há inclusive textos abordando o fim da hegemonia masculina, como o artigo " 0 fim dos homens", de Hanna Rosin (2010, p. 3): "0 homem tem sido o sexo dominante desde 0 alvorecer da humanidade. Mas, pela primeira vez na história humana, este tipo de dominação está mudando com velocidade chocante." o Brasil é um exemplo de país que vem passando por diversas transformações econômicas, sociais e culturais, o que tem possibilitado uma reconfiguração das relações de gênero, como veremos a seguir. 
0 maior país da América Latina passou de uma economia primário-exportadora, sustentada em uma base agrária e rural, para uma economia urbana, sustentada em uma base industrial e de serviços. A transição urbana elevou o percentual da população das cidades de 31,2\%, em 1940, para 84,3\%, em 2010. Paralelamente, houve uma transição demográfica com a passagem de altas para baixas taxas de mortalidade e natalidade, que foi acompanhada por uma transição epidemiológica. Em sequência à transição demográfica teve início a transição da estrutura etária e o consequente processo de mudança de uma sociedade jovem para uma sociedade em processo de envelhecimento. As mudanças nos padrões de família e nas formas de convivência dos arranjos domiciliares são elementos que acompanham e reforçam as demais transformações sociais. Tudo isto tem facilitado a transição de uma sociedade patriarcal para uma sociedade pós-patriarcal, caracterizada por mudanças significativas nas relações de gênero, com maior autonomia e empoderamento das mulheres (ALVES; MARTINE, 2010).

Durante a maior parte do século XX, o Brasil conviveu com os princípios discriminatórios e patriarcais do Código Civil de 1916. Somente com a Constituição Federal de 1988 consagrou-se a igualdade entre homens e mulheres como um direito fundamental. 0 princípio da igualdade entre os gêneros foi endossado no âmbito da sociedade e da família, neste caso, quando o texto estabelece que os direitos e deveres referentes à sociedade conjugal são exercidos igualmente pelos homens e pelas mulheres. As definições constitucionais foram gradativamente convertidas em legislação ordinária, cujo significado é relevante para a implementação da CIPD do Cairo/94 no Brasil, como, por exemplo, o Estatuto da Criança e do Adolescente (Lei n. 8.069 de 13/07/1990), a "Lei do concubinato" (Lei no 8.971) de 29/12/1994, a Lei do Planejamento Familiar (Lei 9.263/1996), o Estatuto do Idoso (Lei n. 10.741 de 01/10/2003) e o novo Código Civil brasileiro (Lei 10.406, de 10/1/2002). Estes avanços possibilitaram não apenas a redução das desigualdades de gênero, mas como mostraram Alves e Correa (2009) passou a existir no país "desigualdades reversas" de gênero, além de crescentes desigualdades intra-gênero. Para se analisar a situação da equidade de gênero na sociedade brasileira é preciso considerar não apenas os indicadores que apontam para as situações de desvantagem social das mulheres, mas também as desigualdades em sentido contrário, ou seja, aquelas que desfavorecem o sexo masculino.

\section{a) Desigualdades de gênero na saúde}

0 aumento da esperança de vida, para ambos os sexos, é uma pré-condição para o desenvolvimento econômico e social de qualquer país. A realização do potencial dos indivíduos só poder ocorrer plenamente quando se supera a mortaliade precoce que ceifa 
a vida de homens e mulheres. 0 gráfico 1, mostra os dados sobre a esperança de vida ao nascer, por sexo, no Brasil. Para ambos os sexos, a esperança de vida passou de 70,5 anos no ano 2000 para 73,2 anos em 2009. No mesmo período, os homens passaram de 66,7 anos para 69,4 anos e as mulheres de 74,4 anos para 77 anos. Portanto, a diferença de cerca de 7,5 anos tem se mantido na última década, favorecendo as mulheres. Estas diferenças de gênero se mantém em termos regionais, embora, para ambos os sexos, nota-se um processo de convergência entre a esperança de vida das regiões menos desenvolvidas e as mais desenvolvidas, ainda que o Nordeste esteja bem abaixo das demais. Esta maior esperança de vida ao nascer das mulheres brasileiras é responsável pelo crescente superávit de mulheres existentes na população brasileira, mesmo considerando que a razão de sexo dos nascidos vivos no país tem permanecido em torno de 105 meninos para cada 100 meninas.

Gráfico 1 - Esperança de vida ao nascer, por sexo, Brasil - 2000- 2009

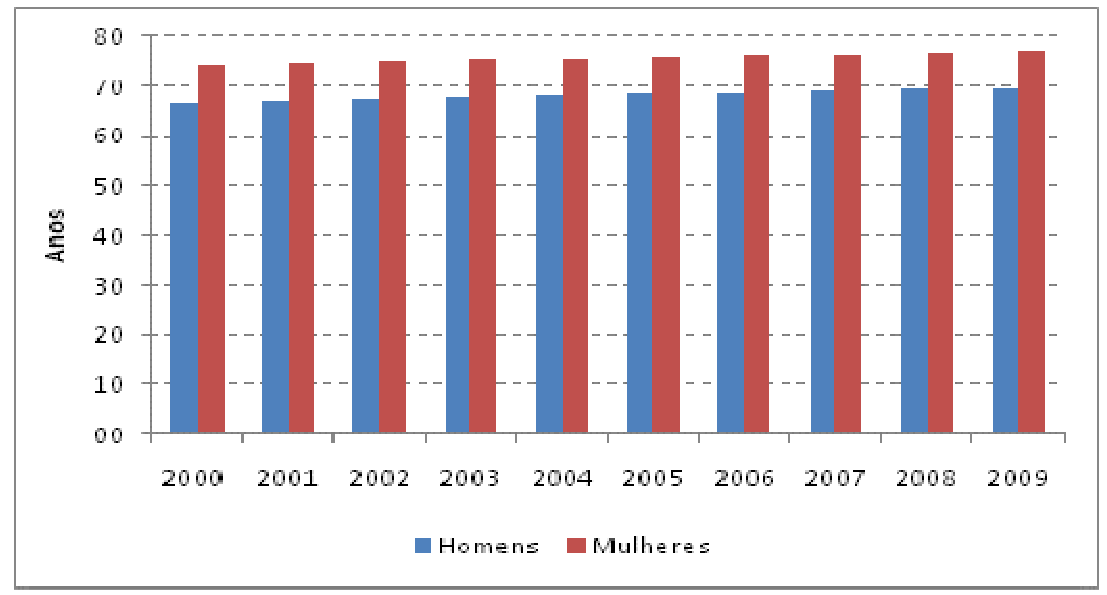

Fonte: Brasil (2010).

Porém, a sobremortalidade masculina no Brasil - diferentemente do que acontece na Ásia - se manisfesta desde o primeiro ano de vida e continua a longo do ciclo de vida. 0 gráfico 2 mostra que, até 1980, existia um certo equilíbrio na razão de sexo no país (próxima de 100). A partir dos anos 80, o superávit de mulheres no país iniciou um processo de ampliação, o que contrasta com o superávit de homens no mundo (razão de sexo acima de 100). 
Gráfico 2 - Razão de sexo no Brasil e no mundo e superavit de mulheres no Brasil, 1950-2050.

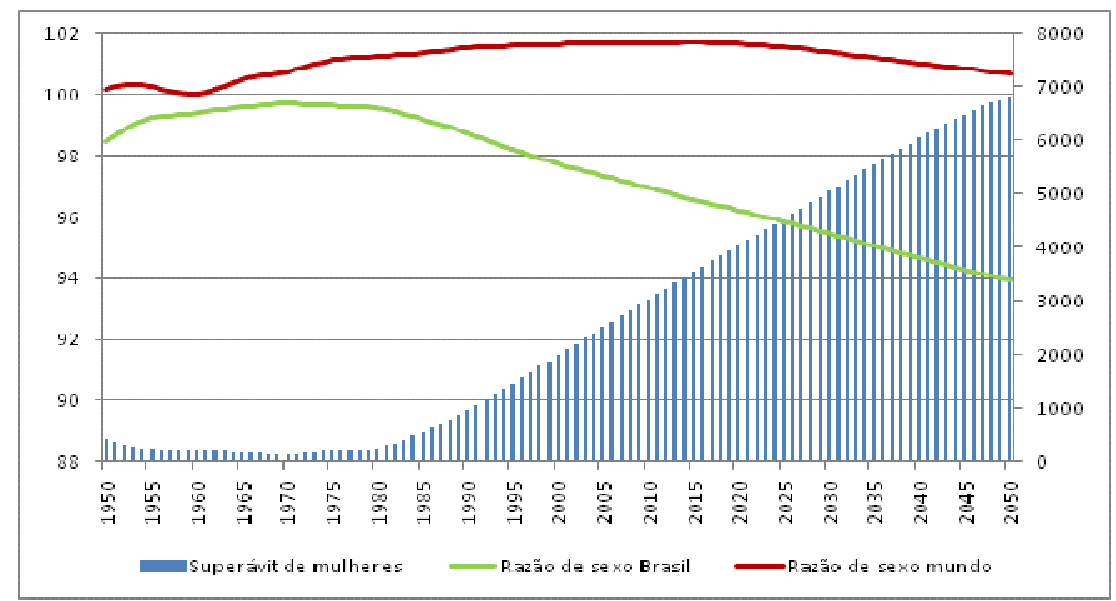

Fonte: UNITED NATIONS/ESA (2011).

0 excedente de mulheres no Brasil, que no início dos anos 80 era de duas centenas de milhares, passou para um milhão no início dos anos 90, dois milhões no início dos anos 2000 e ultrapassou os 3 milhões em 2010. Estima-se que este superávit chegue a 7 milhões no ano 2050. Depois da Rússia, o Brasil é, entre as grandes nações, o país mais feminino do mundo. 0 excesso de mulheres está concentrado nas áreas urbanas e é crescente com o avanço das idades.

Em grande parte, a feminização da população brasileira pode ser explicada pelo aumento das mortes por causas externas (acidentes de trânsito e violências), que é uma epidemia que atinge, em maior proporção, os homens e tem afetado a dinâmica demográfica do Brasil a partir dos anos de 1980. 0 gráfico 3 mostra o número de óbitos por causas externas, por sexo, entre 1991 e 2010. Nota-se que o número de mortes masculinas ficou acima de 100 mil por ano na última década e o número de mortes femininas ficou acima de 20 mil a partir de 2004. Nos 20 anos em questão, morreram 2.010.426 homens e 400.914 mulheres. A proporção de mortes masculinas foi de 5 para 1, em relação às mortes femininas. Entre 1991 e 2010 o número de mortes por causas externas foi de 2,01 milhões para os homens e de 400,9 mil para as mulheres. Portanto, a sobremortalidade masculina por causas externas foi de 1,6 milhão, o que representa $77 \%$ do aumento do superávit feminino na população brasileira, no período. 
Gráfico 3 - Número de óbitos por causas externas, por sexo, Brasil, 1991-2010.

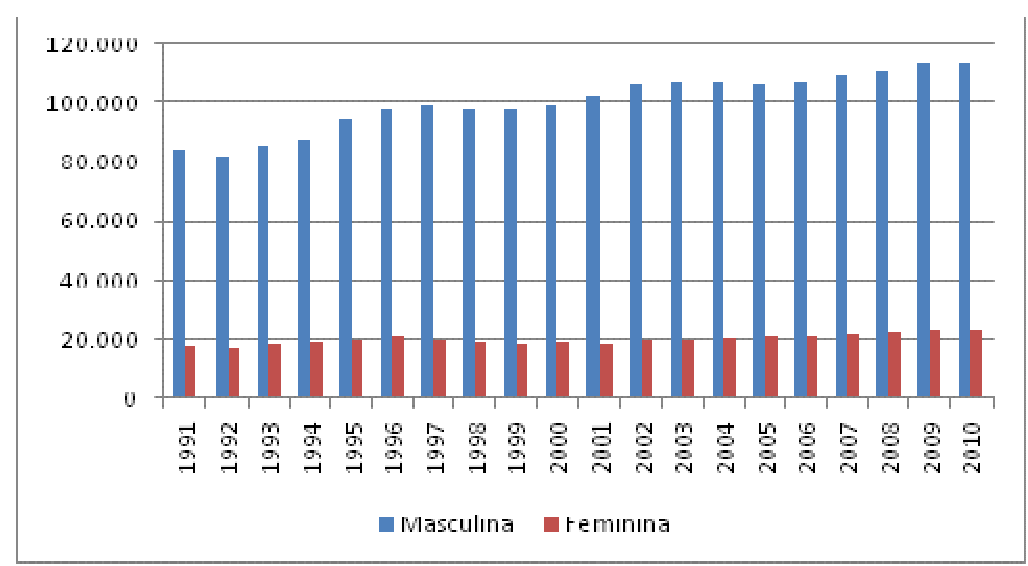

Fonte: Brasil (2010).

Nota: $2010=$ dados preliminares.

Os dados do Ministério da Saúde sobre os óbitos por causas externas, segundo tipos de causas, para o ano de 2008, mostram que os acidentes mataram 47.354 homens (42,6\%), as Violências 52.258 homens (47,1\%) e as mortes classificadas como intenção indeterminada e demais causas ceifaram a trajetória de outros 11.453 homens (10,4\%). Somente os homicídios eliminaram a vida de 45.064 homens, em 2008. A maioria dos mortos do sexo masculino estava na faixa dos 20 aos 39 anos (50,4\%) e era de cor parda (48,1\%), segundo o Ministério da Saúde (2011). No caso das mulheres, a maioria das mortes por causas externas deveu-se aos acidentes, sendo 12.978 mortes, o que representou $57,8 \%$ do total de mortes femininas. As violências vêm em segundo lugar, com 5.781 óbitos, representando $25,8 \%$ do total de mortes femininas. 0 perfil etário e étnico das mulheres que perderam a vida por causas externas é diferente. Do total de vítimas femininas, 33,8\% tinham 60 anos ou mais, sendo a maioria (53,3\%) de cor branca.

A morte é um evento inexorável, porém, os óbitos por causas externas não são fatalidades biológicas, mas sim mortes que poderiam ser evitadas com ações de infraestrutura para evitar os acidentes e políticas públicas para diminuir a violência. 0 custo social destas mais de 130 mil mortes anuais por causas externas no Brasil é incalculável. Os pais perdem os filhos que criaram com sacrifício e carinho. Esposas e maridos perdem seus cônjuges. Filhos perdem seus pais. Famílias são dilaceradas e colocadas em situação de vulnerabilidade. Empresas perdem seus empregados e a sociedade perde seus cidadãos, principalmente nas idades mais produtivas em termos econômicos, sociais e culturais. 
Além disto, existem outros custos para a sociedade e para o sistema de saúde, pois as internações por causas externas representaram cerca de 8\% do total de internações em 2008 (foi o quinto maior motivo de hospitalizações). Isso significa que, para cada morte, aproximadamente sete pessoas são internadas. São muitos anos de vida perdidos pela mortalidade ou morbidade. Os orçamentos dos ministérios da saúde e da previdência são os mais afetados. Portanto, existe uma desigualdade reversa de gênero, com os homens sendo as principais vítimas das mortes por causas externas. Mas o desequílibrio também acontece, mesmo que em menor proporção, devido à sobremortalidade masculina por AIDS.

0 gráfico 4 mostra o número de óbitos por AIDS, por sexo, e a percentagem de mortes femininas, no Brasil, entre 1991 e 2010. Nota-se que o número de mortes masculinas atingiu o máximo em 1995, com 11.599 óbitos e começou a cair até chegar em 7.753 óbitos em 2009/2010. 0 número de mortes femininas passou de 1.229 óbitos em 1991, para 3.828, em 1996, caindo ligeiramente nos anos seguintes e atingindo 0 máximo de 4.060 óbitos, em 2009/2010. Nos vinte anos em questão, morreram 163.447 homens e 65.257 mulheres, por causa da AIDS. 0 percentual de óbitos femininos dobrou, passando de 17\%, em 1991, para 34\%, em 2010. Mesmo assim, ainda morrem 2 homens para cada mulher e, nas duas décadas apresentadas no gráfico, morreram no total quase 100 mil homens a mais do que mulheres.

Gráfico 4 - Número de óbitos de AIDS, por sexo, percentagem de mortes femininas, Brasil, 1991-2010

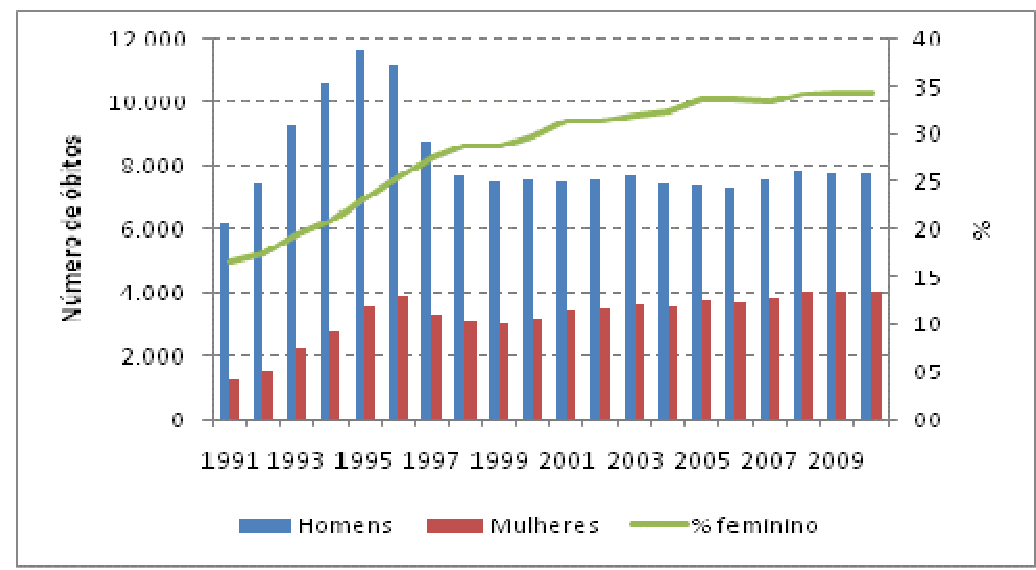

Fonte: Brasil (2010).

Nota: $2009=$ dados preliminares; $2010=$ estimativa. 
Este desequilîbrio na razão de sexo da população adulta brasileira pode trazer diversas consequências ainda não suficientemente estudadas. A chamada "pirâmide da solidão" é uma constatação de que o número de mulheres sozinhas (sem cônjuge) cresce com o avanço da idade e devido à sobremortalidade masculina. Um desequilíbrio que já pode ser notado acontece no chamado "mercado matrimonial", especialmente nas áreas urbanas que concentram maior percentual da população feminina.

\section{b) Desigualdades de gênero na educação}

Além da saúde, a educação é outra área em que houve um grande avanço das mulheres e hoje existe uma desigualdade reversa, com o sexo feminino apresentando maiores níveis educacionais do que o sexo masculino (Beltrão e Alves, 2009). A tabela 1 mostra a evolução da média de anos de estudo de instrução formal, para a população de 15 anos e mais, para o Brasil, regiões e algumas categorias, no período 1992 a 2009. Embora a educação brasileira esteja abaixo da média e da qualidade daquela de outros países com o mesmo nível de desenvolvimento, os dados mostram uma evolução geral positiva, com redução das desigualdades regionais, raciais, situação de domicílio, etc.

Os anos médios de estudo da população brasileira era de 5,2 anos, em 1992, e passou para 7,5\%, em 2009, aumento de 44\% no período. Entre as regiões o Nordeste apresentou as menores médias de anos de estudo: 3,8 anos em 1992 e 6,3 anos em 2009, mas a variação obtida no período significou um aumento de $65 \%$, bem acima das demais regiões. Portanto, houve redução nas desigualdades regionais. Em termos de situação de domicílio, as melhores médias são encontradas nas áreas metropolitanas, seguidas das áreas urbanas não metropolitanas e, por último, no meio rural. Porém, foram as áreas rurais que apresentaram o maior aumento, passando de 2,6 anos, em 1992, para 4,8 anos, em 2009, variação de 82\% no período. 
Tabela 1 - Média de anos de estudos, segundo categorias selecionadas - Brasil 1992 a 2009

\begin{tabular}{|l|c|c|c|c|c|c|c|c|c|c|c|c|c|c|c|c|}
\hline \multicolumn{1}{|c|}{ Categorias } & 1992 & 1993 & 1995 & 1996 & 1997 & 1998 & 1999 & 2001 & 2002 & 2003 & 2004 & 2005 & 2006 & 2007 & 2008 & 2009 \\
\hline Brasil & 5,2 & 5,3 & 5,5 & 5,7 & 5,7 & 5,9 & 6,1 & 6,4 & 6,5 & 6,7 & 6,8 & 6,9 & 7,1 & 7,3 & 7,4 & 7,5 \\
\hline Região & & & & & & & & & & & & & \\
\hline Norte & 5,4 & 5,3 & 5,5 & 5,6 & 5,7 & 5,8 & 6,1 & 6,3 & 6,5 & 6,6 & 6,2 & 6,4 & 6,6 & 6,8 & 7,0 & 7,1 \\
\hline Nordeste & 3,8 & 4,0 & 4,1 & 4,3 & 4,3 & 4,5 & 4,6 & 4,9 & 5,1 & 5,3 & 5,5 & 5,6 & 5,8 & 6,0 & 6,2 & 6,3 \\
\hline Sudeste & 5,8 & 6,0 & 6,2 & 6,3 & 6,4 & 6,6 & 6,7 & 7,1 & 7,2 & 7,4 & 7,5 & 7,6 & 7,8 & 8,0 & 8,1 & 8,2 \\
\hline Sul & 5,6 & 5,7 & 5,9 & 6,1 & 6,1 & 6,3 & 6,5 & 6,7 & 7,0 & 7,2 & 7,3 & 7,4 & 7,6 & 7,6 & 7,8 & 7,9 \\
\hline Centro-Oeste & 5,4 & 5,5 & 5,6 & 5,8 & 6,0 & 6,1 & 6,2 & 6,5 & 6,8 & 6,9 & 7,1 & 7,2 & 7,4 & 7,5 & 7,7 & 7,9 \\
\hline Localização & & & & & & & & & & & & & & \\
\hline Metropolitano & 6,6 & 6,7 & 6,9 & 7,0 & 7,1 & 7,3 & 7,4 & 7,6 & 7,8 & 8,0 & 8,1 & 8,2 & 8,5 & 8,5 & 8,6 & 8,7 \\
\hline Não Metropolitano & 5,4 & 5,4 & 5,6 & 5,8 & 5,9 & 6,0 & 6,2 & 6,4 & 6,6 & 6,8 & 6,9 & 7,0 & 7,2 & 7,3 & 7,5 & 7,6 \\
\hline Rural & 2,6 & 2,8 & 2,9 & 3,1 & 3,1 & 3,3 & 3,4 & 3,4 & 3,6 & 3,8 & 4,0 & 4,1 & 4,3 & 4,5 & 4,6 & 4,8 \\
\hline Sexo & & & & & & & & & & & & & \\
\hline Masculino & 5,1 & 5,2 & 5,4 & 5,6 & 5,6 & 5,8 & 5,9 & 6,2 & 6,4 & 6,6 & 6,7 & 6,8 & 7,0 & 7,1 & 7,2 & 7,4 \\
\hline Feminino & 5,2 & 5,4 & 5,6 & 5,7 & 5,8 & 6,0 & 6,2 & 6,5 & 6,7 & 6,8 & 7,0 & 7,1 & 7,3 & 7,4 & 7,6 & 7,7 \\
\hline Raça ou Cor & & & & & & & & & & & & & & \\
\hline Branca & 6,1 & 6,2 & 6,4 & 6,5 & 6,7 & 6,8 & 7,0 & 7,3 & 7,4 & 7,6 & 7,7 & 7,8 & 8,0 & 8,1 & 8,3 & 8,4 \\
\hline Negra & 4,0 & 4,1 & 4,3 & 4,5 & 4,5 & 4,7 & 4,9 & 5,2 & 5,5 & 5,7 & 5,8 & 6,0 & 6,2 & 6,3 & 6,5 & 6,7 \\
\hline Faixa Etária & & & & & & & & & & & & \\
\hline 15 a 24 anos & 5,8 & 5,9 & 6,2 & 6,3 & 6,5 & 6,8 & 7,0 & 7,4 & 7,7 & 8,0 & 8,1 & 8,3 & 8,4 & 8,5 & 8,7 & 8,8 \\
\hline 25 a 29 anos & 6,5 & 6,6 & 6,7 & 6,8 & 6,9 & 7,0 & 7,2 & 7,5 & 7,7 & 8,0 & 8,1 & 8,4 & 8,7 & 8,9 & 9,2 & 9,4 \\
\hline 30 a 39 anos & 6,1 & 6,2 & 6,4 & 6,6 & 6,7 & 6,8 & 6,8 & 7,0 & 7,2 & 7,3 & 7,5 & 7,6 & 7,8 & 7,9 & 8,1 & 8,2 \\
\hline 40 anos + & 3,8 & 3,9 & 4,2 & 4,3 & 4,4 & 4,6 & 4,7 & 5,0 & 5,2 & 5,3 & 5,4 & 5,5 & 5,7 & 5,9 & 6,0 & 6,2 \\
\hline
\end{tabular}

Fonte: Intituto de Pesquisa Econômica Aplicada - IPEA (2010).

Em termos de faixa etária, o grupo de 25-29 anos de idade permanece na liderança da média de anos de estudo, com 6,5 anos, em 1992 e 9,4 anos, em 2009, aumento de 45\%, no período. Já o grupo de 40 anos e mais de idade apresenta as menores médias de escolaridade. Isto significa que, com o passar do tempo, a educação média do Brasil vai aumentar, pois as gerações mais novas possuem níveis de instrução maiores do que os das gerações mais idosas. Isto reflete a melhoria no grau de cobertura que aconteceu nas duas últimas décadas. Em termos de raça/cor, houve melhora geral entre 1992 e 2009, com a população branca passando de 6,1 anos de estudo médios, para 8,4 anos (aumento de 37\%) e a população negra (preta + parda) passando de 5,2 anos para 6,7 anos (aumento de 68\%). É preciso registrar que existem desigualdes transversais, pois uma parcela maior da população negra vive no Nordeste e nas áreas rurais, sendo que o quesito cor na verdade capta uma parte das desigualdades regionais e de situação de domicílio. Isto fica claro quando existe uma melhora conjunta dos níveis educacionais da população por cor/raça, do Nordeste e das áreas rurais. 
Em termos de desigualdades de gênero, os homens tinham 5,1 anos médios de estudo em 1992 e passaram para 7,4 anos, em 2009 (aumento de 44\%). Já as mulheres tinham 5,2 anos de estudo, em 1992, e passaram para 7,7 anos, em 2009 (aumento de 47\%). Portanto, as mulheres possuem níveis médios de instrução maiores do que os dos homens e esta diferença está aumentando, a favor das mulheres. Isto é o exemplo clássico de desigualdade reversa, pois as mulheres tiveram maiores dificuldades de acesso à escola na maior parte dos 500 primeiros anos da história do Brasil, mas ultrapassaram os homens e estão ampliando a vantagem conquistada.

0 processo de reversão das desigualdades de gênero no Brasil aconteceu ao longo de décadas (BELTRÃO; ALVES, 2009). Mesmo as mulheres brasileiras ainda sendo maioria entre a população analfabeta, isto só acontece pelo peso da exclusão das mulheres das gerações mais idosas. Nas gerações mais jovens, as mulheres conseguiram superar os homens no ensino fundamental e, especialmente, no ensino médio e superior. Neste último, $60 \%$ dos formandos são do sexo feminino. Mais recentemente, a partir de 2004, as mulheres são maioria também entre os titulados dos cursos de doutorado no Brasil.

Em síntese, os dados mostram que as mulheres tiveram ganhos educacionais inequívocos nas últimas décadas. A despeito da qualidade da educação brasileira, a análise dos diferenciais de educação entre homens e mulheres, mostra que o "sexo fraco" está cada vez mais forte, quando o assunto é níveis de escolaridade. Em outras dimensões sociais e econômicas da sociedade, particularmente no mercado de trabalho, os diferenciais de gênero ainda são grandes, com as mulheres em desvantagem. Mas quando se trata de observar o hiato de gênero na educação, o Brasil já superou as metas estabelecidas na CIPD do Cairo/1994 e nos Objetivos do Desenvolvimento do Milênio. Hoje, nesta área, as desigualdades são reversas. 0 desafio atual é incrementar a educação dos homens e melhorar a qualidade da educação para ambos os sexos.

\section{c) Desigualdades de gênero no mercado de trabalho}

Embora as mulheres tenham revertido as desigualdades de gênero na educação, ainda não conseguiram eliminar as desigualdades de gênero no mercado de trabalho, mesmo que os hiatos de atividade e rendimento tenham se reduzido. 0 desenvolvimento econômico e social de um país depende do pleno emprego dos insumos produtivos disponíveis e do crescimento da produtividade dos fatores de produção, especialmente das mulheres que são mais da metade da população e possuem dificuldades para uma inserção de qualidade no mercado de trabalho.

0 Brasil apresentou um grande crescimento da População Economicamente Ativa (PEA) nas últimas 6 décadas. A PEA total passou de 17,1 milhões de pessoas, em 
1950, para quase 101,1 milhões de pessoas, em 2009 (aumento de 5,9 vezes). A PEA masculina passou de 14,6 milhões para 56,7 milhões (incremento de 3,9 vezes), enquanto a PEA feminina teve uma elevação extraordinária, passando de 2,5 milhões, em 1950, para 44,4 milhões, em 2007 (crescimento de 17,8 vezes). Parte desta expansão deve-se a mudanças metodológicas nos instrumentos de coleta do censo e das pesquisas domiciliares, mas a tendência de aumento de longo prazo é inegável e são as mulheres a principal força por detrás do crescimento da força de trabalho no Brasil.

0 Gráfico 5 mostra o comportamento das taxas de atividade para homens e mulheres, entre 1950 e 2009. Observa-se redução das taxas masculinas, que passaram de 80,8\% em 1950 para 72,3\% em 2009 e aumento das taxas femininas, que passaram de 13,6\% para 52,7\%, no mesmo período. A linha do gráfico mostra a tendência de decréscimo do hiato de gênero, já que existe um processo de convergência no nível de inserção de ambos os sexos na população economicamente ativa. Evidentemente, o aumento da participação feminina no mercado de trabalho não eliminou os problemas de segregação ocupacional e discriminação salarial, embora tenham sido abrandados, como será visto mais adiante.

Gráfico 5 - Taxas de participação na PEA, por sexo, Brasil - 1950-2009

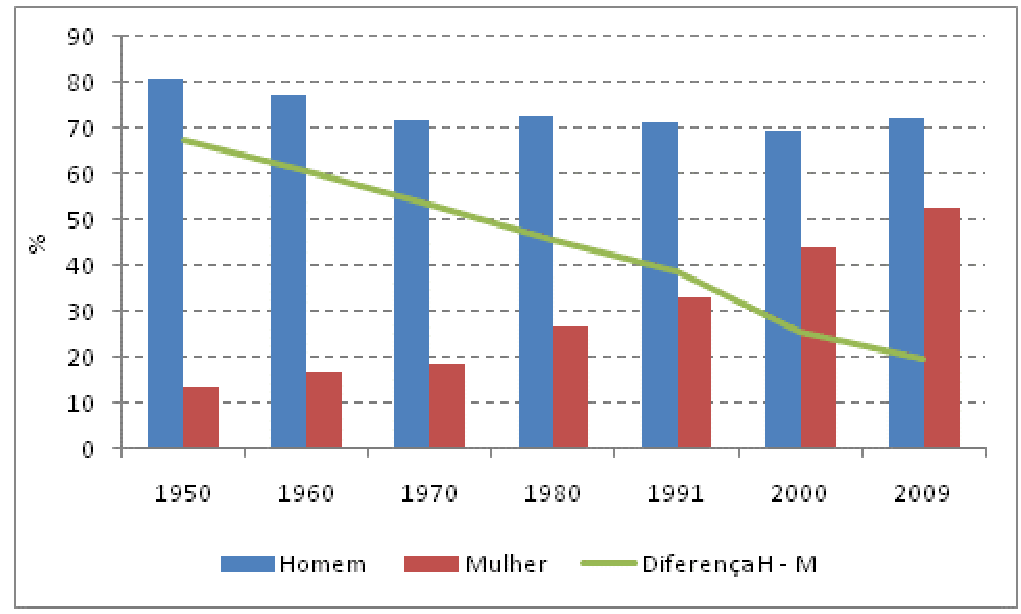

Fonte: IBGE censos demográficos de 1950 a 2000 e PNAD 2009

Alguns estudiosos consideram que este aumento da participação feminina no mercado de trabalho ocorreu em função da necessidade de uma complementação da renda familiar por parte das mulheres (cônjuges ou filhas), em uma situação de redução do rendimento per capita. Contudo, como mostraram Alves e Correa (2009) esta argumentação não considera que as mulheres continuam se inserindo no mercado 
de trabalho nos momentos de aumento da renda domiciliar e são, principalmente, aquelas com maior nível educacional (e com salários acima do salário mínimo) que possuem as maiores taxas de atividade, inclusive as que moram sozinhas.

0 gráfico 6 mostra que, na última década, houve significativa melhora do nível educacional da população ocupada. Para as força de trabalho feminina, o grupo de mulheres com 11 ou mais anos de estudo é maioria, empatando em termos absolutos e relativos com os homens de mesmo nível educacional. Um fato que merece destaque é que para o conjunto da PEA com 11 anos ou mais de estudo, as mulheres superaram os homens neste segmento mais escolarizado, sendo que em 2009 já existiam mais de 20 milhões de mulheres com mais de 11 anos de estudo na PEA.

Gráfico 6 - Percentagem da PEA por grupos de anos de estudo, por sexo, Brasil, 2001-2009

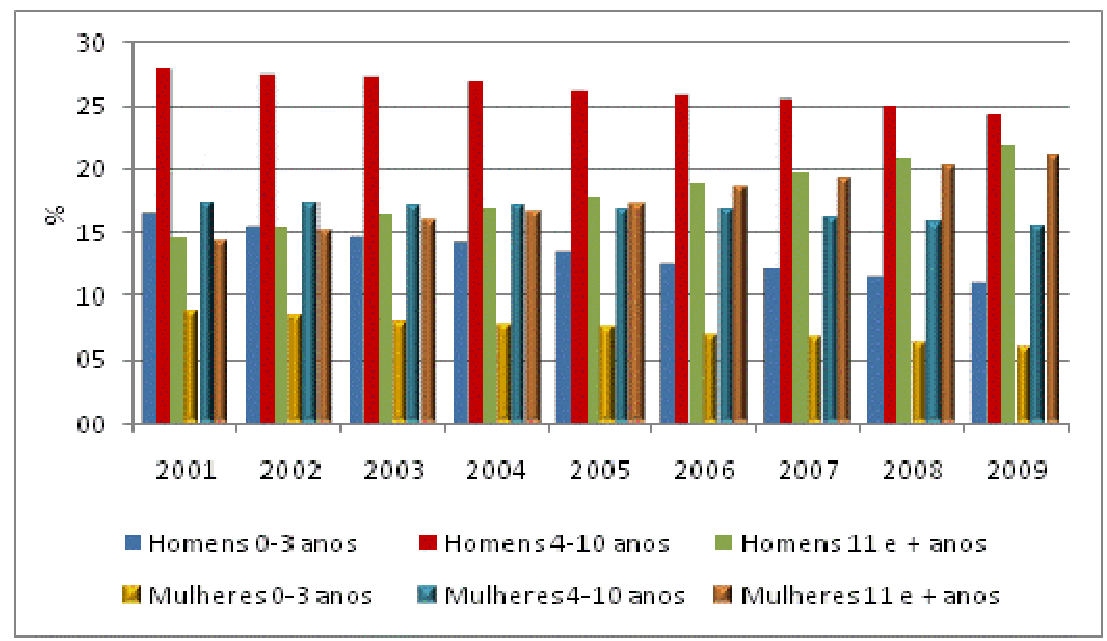

Fonte: IBGE (2009).

Em termos de remuneração, entretanto, as mulheres continuam em desvantagem. 0 gráfico 7 mostra a relação entre rendimento-hora da população feminina em relação à masculina, segundo classes de anos de estudo. Observa-se que as mulheres ganham menos do que os homens, porém esta diferença tem diminuido. Em 1998 as mulheres recebiam $81,9 \%$ do rendimento dos homens e passaram a receber 84,1\% em 2008. Nota-se que os diferenciais de gênero aumentam com o nível de escolaridade, o que pode estar relacionado com a dificuldade das mulheres ocuparem os 
postos de decisão e administração e também ao fato de que estes diferenciais são maiores nas gerações com maior tempo de ocupação.

Gráfico 7 - Relação entre rendimento-hora da população feminina em relação à masculina, segundo classes de anos de estudo - Brasil, 1998 e 2008

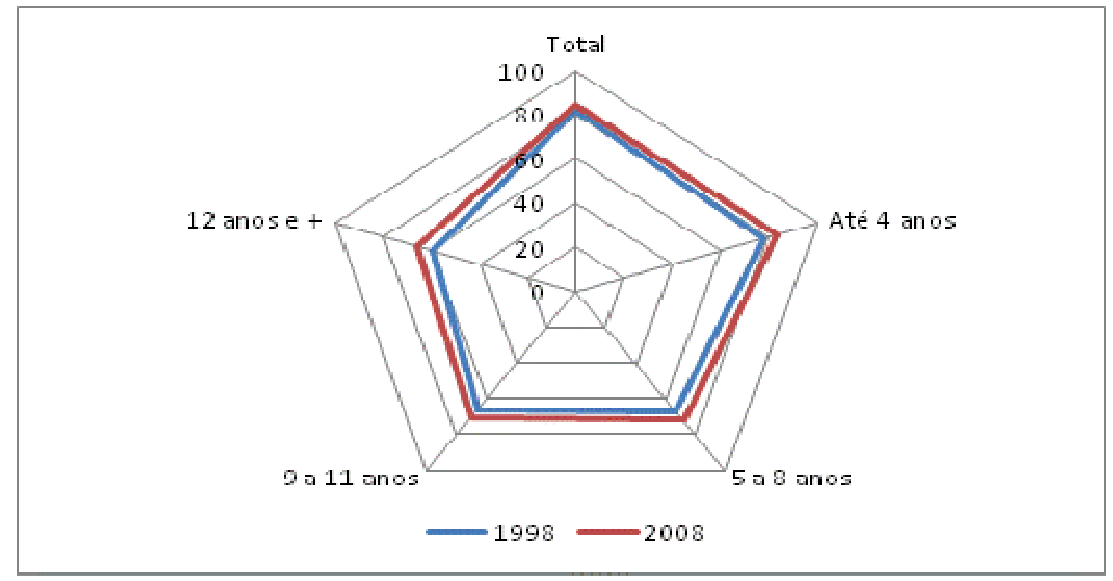

Fonte: Intituto de Pesquisa Econômica Aplicada - IPEA (2010).

Outro fator que contribui para as desigualdades de gênero é que o grau de informalidade e o desemprego das mulheres se manteve mais elevado do que o dos homens durante a década passada, embora a População Economicamente Ativa (PEA) feminina tenha crescido mais rapidamente do que a masculina. Um dos fatores que contribui para o desequilíbrio entre oferta e demanda é a segregação ocupacional que torna o leque de profissões femininas mais estreito do que o masculino. Assim, ao oferecer mais opções para os homens, o mercado atingiria um equilíbrio em um nível mais baixo de desemprego masculino, enquanto a disputa pelas poucas ofertas de emprego feminino torna o desemprego das mulheres e a informalidade um fenômeno mais frequente.

Este quadro poderia mudar na medida em que houvesse um quadro de pleno emprego na economia. De fato, como mostra 0 gráfico 8, o grau de informalidade no mercado de trabalho e o desemprego vinham diminuindo de 2004 a 2008. A crise do ano 2009 não aumentou o grau de informalidade, nem de homens e nem de mulheres. Neste sentido, para o período em questão, não tem fundamento a afirmação de que a entrada da mulher no mercado de trabalho é acompanhada por "perda de direitos legais". Porém, houve uma elevação da taxa de desemprego para ambos os sexos durante a crise de 2009 e uma redução a partir da recuperação da economia. Com base na Pesquisa 
Mensal de Emprego, para as seis maiores regiões metropolitanas do país, pode-se dizer que o desemprego se reduziu em 2010 e existe a perspectiva de se atingir o pleno emprego no quinquênio 2011-2015.

Gráfico 8 - Grau de informalidade: percentagem de pessoas de 10 anos e mais de idade, ocupadas na semana de referência e que não contribuiram para a previdência, por sexo, Brasil, 2002-2009

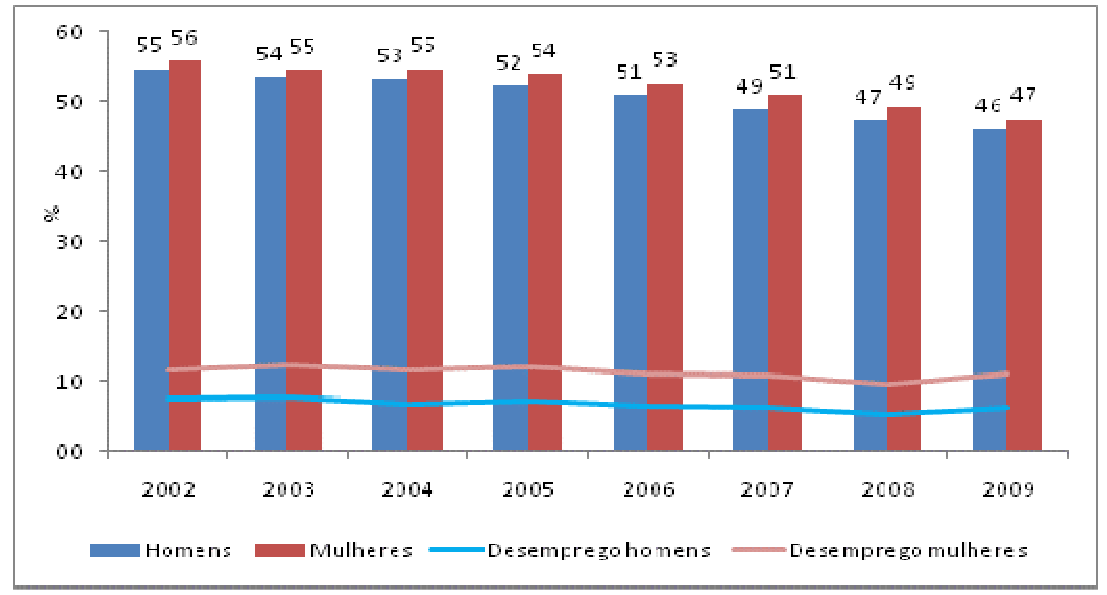

Fonte: IBGE (2009).

0 gráfico 9, com base na Pesquisa Mensal de Emprego (PME) do IBGE, mostra que a população economicamente ativa (PEA) e a taxa de atividade que vinham subindo durante 0 ano de 2008, diminuiram no início de 2009 para ambos os sexos. No segundo semestre de 2009, a PEA e a taxa de atividade feminina começaram a subir levemente para a população feminina, tendência que se manteve em 2010. 
Gráfico 9 - Pessoas de 10 anos ou mais de idade, economicamente ativas na semana de referência (Mil pessoas), seis regiões metropolitanas, janeiro de 2008 a novembro de 2010

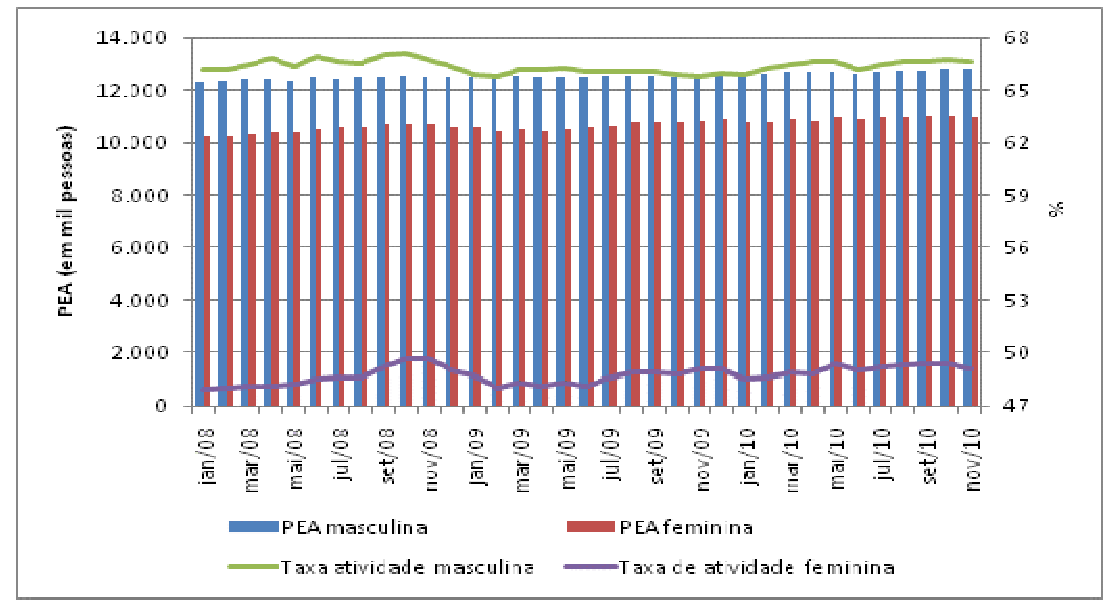

Fonte: IBGE (2010).

Já para a PEA e a taxa de atividade masculina se mantiveram constantes, em 2009, e só voltaram a subir em 2010. De janeiro de 2008 a novembro de 2010 a PEA masculina cresceu $4,2 \%$ e a PEA feminina cresceu $6,5 \%$. Embora a PEA tenha crescido pouco, a taxa de desemprego teve uma redução significativa ao longo do ciclo econômico que teve início em 2004. Os dados da PME mostram que a taxa de desemprego, das pessoas de 10 anos ou mais de idade, nas 6 regiões metropolitanas, para o sexo masculino caiu de 11\%, em meados de 2003 para 4,3\% em novembro de 2010. Para o sexo feminino, o desemprego caiu de 16\% em meados de 2003 para 7,4\% em novembro de 2010.

Os dados acima mostram que, embora ainda persistam desigualdades que desfavorecem as mulheres no mercado de trabalho, as diferenças de gênero têm diminuido ao longo dos anos. Para completar esta análise é preciso considerar a política de previdência social que pode ter o poder de amenizar as desigualdades do mundo do trabalho.

A Tabela 2 mostra que, mesmo sendo um contingente minoritário no mercado de trabalho, as mulheres predominam entre a população coberta pela previdência social. Considerando-se somente os aposentados, os homens são maioria, passando de 7,6 milhões, em 2001, para 9,3 milhões, em 2009. Entre os pensionistas, as mulheres são ampla maioria, passando de 3,7 milhões, em 2001, para 4,3 milhões, em 2009. 
Somando-se os aposentados e pensionistas, as mulheres eram 10,2 milhões em $2001 \mathrm{e}$ passaram para 13,1 milhões em 2009, enquanto os homens correspondiam a 8,1 milhões e 10,2 milhões, no mesmo período.

Entre as pessoas que acumulam aposentadoria e pensão, o sexo feminino também predomina e as mulheres já somavam 1,6 milhão de pessoas nesta situação, em 2009. Pode-se considerar que a política previdenciária brasileira tem um desenho prómulher, já que o sexo feminino, em média, contribui por menos tempo e passa mais tempo na situação de beneficiárias, quer seja como aposentadas ou pensionistas.

Tabela 2 - Número de pessoas aposentadas e/ou pensionistas (em mil), segundo sexo, Brasil - 2001-2009

\begin{tabular}{|c|c|c|c|c|c|c|c|c|c|c|}
\hline Categorias & Sexo & 2001 & 2002 & 2003 & 2004 & 2005 & 2006 & 2007 & 2008 & 2009 \\
\hline $\begin{array}{c}\text { Total de } \\
\text { aposentados e } \\
\text { pensionistas }\end{array}$ & Total & 15.333 & 16.176 & 16.920 & 17.663 & 18.214 & 19.077 & 19.955 & 22.784 & 23.359 \\
\cline { 2 - 13 } & Momem & 8.065 & 8.363 & 8.763 & 8.735 & 9.047 & 9.201 & 9.623 & 9.862 & 10.236 \\
\hline \multirow{2}{*}{$\begin{array}{c}\text { Somente } \\
\text { aposentados }\end{array}$} & 10.232 & 10.762 & 11.216 & 11.311 & 11.823 & 12.000 & 12.503 & 12.922 & 13.123 \\
\hline & Total & 13.252 & 13.829 & 14.328 & 14.206 & 14.531 & 14.853 & 15.273 & 16.195 & 16.522 \\
\cline { 2 - 12 } & Mulher & 7.627 & 7.907 & 8.235 & 8.201 & 8.403 & 8.557 & 8.771 & 9.082 & 9.329 \\
\hline \multirow{2}{*}{$\begin{array}{c}\text { Somente } \\
\text { pensionistas }\end{array}$} & Total & 4.059 & 4.202 & 4.416 & 4.567 & 4.856 & 4.757 & 5.292 & 4.783 & 4.894 \\
\hline & Homem & 341 & 347 & 395 & 406 & 477 & 437 & 642 & 531 & 597 \\
\hline \multirow{2}{*}{$\begin{array}{c}\text { Aposentados e } \\
\text { pensionistas }\end{array}$} & Mulher & 3.718 & 3.855 & 4.021 & 4.160 & 4.379 & 4.321 & 4.651 & 4.252 & 4.297 \\
\hline & Total & 986 & 1.094 & 1.235 & 1.273 & 1.482 & 1.590 & 1.561 & 1.807 & 1.943 \\
\hline & Mulher & 97 & 108 & 133 & 128 & 166 & 207 & 210 & 249 & 310 \\
\hline
\end{tabular}

Fonte: IBGE (2009).

\section{d) Desigualdades de gênero no uso do tempo}

A literatura mostra que as mulheres estão inseridas em menor número do que os homens nas atividades produtivas remuneradas e possuem jornadas mais curtas de trabalho (Alves e Correa, 2009). Mas o contrário acontece com as atividades não remuneradas e os afazeres domésticos. Quando se trata dos trabalhos realizados na esfera da reprodução, mas que não são contabilizados na população economicamente ativa, as mulheres são ampla maioria.

Segundo a PNAD (IBGE, 2005), 109,2 milhões de pessoas de 10 anos ou mais de idade declararam exercer atividades relacionadas com os afazeres domésticos, no Brasil; sendo que, deste conjunto, 71,5 milhões eram mulheres. Em termos absolutos, é a população adulta de 25 a 49 anos de idade que mais realiza afazeres domésticos. Não obstante, considerando a população em cada grupo etário, observa-se que é a população de 50 a 59 anos de idade que despende maior parte do seu tempo em afazeres domésticos (24,3 horas semanais). 
As desigualdades de gênero na realização dessas atividades são ainda mais visíveis quando se considera a população total de acordo com o sexo e os grupos de idade. Verificou-se que somente $51,1 \%$ dos homens realizam afazeres domésticos enquanto que entre as mulheres esse percentual é de 90,6\%. É no Nordeste que se observa a menor participação dos homens nos afazeres domésticos (46,7\%) enquanto que no Sul se evidencia a maior taxa (62\%). Uma possível explicação para esta participação um pouco mais baixa dos homens nordestinos nos afazeres domésticos pode estar ligada aos aspectos culturais locais, que valorizam o "machismo" já que existe uma forte correlação positiva entre a realização de afazeres domésticos e sexo feminino (SOARES; SABÓIA, 2007).

No Gráfico 10, verifica-se que, no total, as mulheres dedicavam 25,1 horas semanais aos afazeres domésticos, contra 10,2 horas dos homens, em 2009. A análise por grupos etários mostra que o tempo dedicado aos afazeres domésticos cresce à medida que aumenta a idade para ambos os sexos. Isto porque os filhos que moram com os pais dedicam menos tempo aos afazeres domésticos. Mas o destaque mais contrastante é a grande diferença entre o tempo dedicado aos afazeres domésticos por ambos os sexos.

Além disto, apenas 49\% dos homens contra 88,2 das mulheres fazem trabalhos domésticos. A sobregarca de trabalho doméstico (ou da economia do cuidado) contribui para a inserção da mulher na PEA, para a menor jornada diária e para a maior preença feminina nos empregos informais. A dupla ou tripla jornada feminina é um dos elementos centrais da desigualdade de gênero entre atividades produtivas e reprodutivas.

Gráfico 10 - Número médio de horas semanais gastas em afazeres domésticos das pessoas de dez anos ou mais de idade, por sexo, segundo grupos de idade, Brasil - 2009

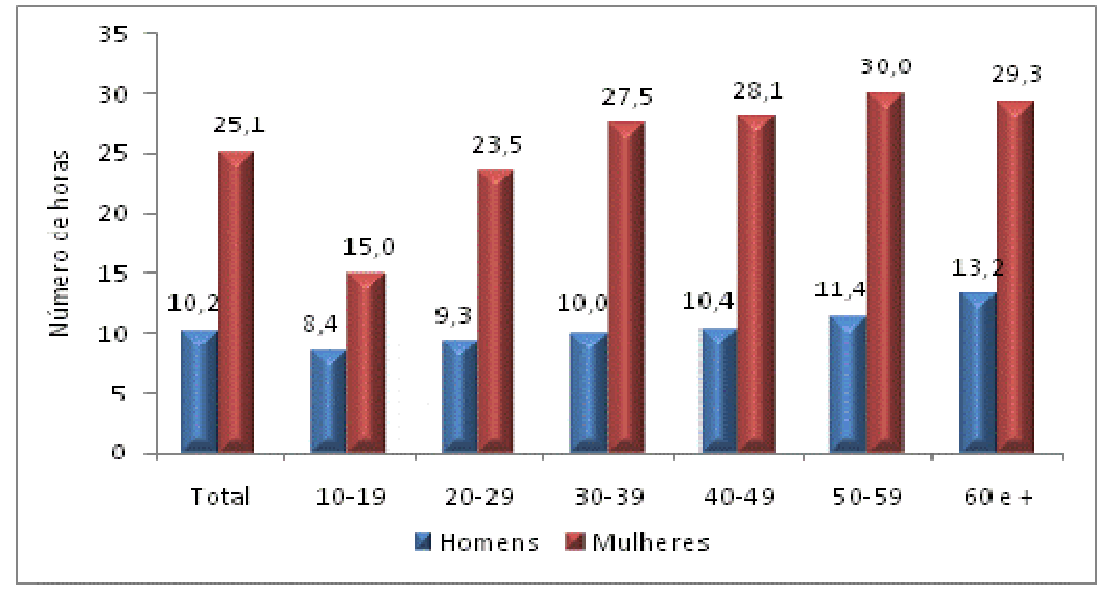

Fonte: IBGE: PNAD 2009 
Por exemplo, famílias com muitos filhos pequenos exigem maior presença feminina no cuidado de seus membros, já que existe uma divisão sexual do trabalho que limita o potencial produtivo das mulheres ao responsabilizá-las pela economia do cuidado. 0 direito da mulher ao emprego remunerado tem obtido apoio crescente, inclusive de organizações empresariais. Klaus Schwab (2009, p. v), fundador e Chefeexecutivo do World Economic Fórum, de Davos, na Suíça, escreveu o seguinte no prefácio do relatório do Global Gender Gap Index:

Durante o ano passado, o mundo passou pela maior recessão, em quase um século. É claro que a recuperação vai exigir, entre outras coisas, o melhor do talento, das idéias e da inovação. Portanto, é mais importante agora do que nunca que os países e as empresas prestem atenção a um dos fundamentais pilares do crescimento econômico de que dispõem: as habilidades e os talentos dos recursos humanos do sexo feminino. (traduzido pelos autores)

A economia do cuidado envolve a criação dos filhos, a guarda das crianças, a atenção com os parentes idosos ou com necessidades especiais, as atividades de educação, saúde e dos afazeres domésticos, assim como a convivência das pessoas que cuidam umas das outras e do ambiente natural. No entanto, da economia do cuidado depende toda a reprodução humana e, portanto, a própria existência da produção e do mercado.

Segundo o informe da Comissão Econômica para a América Latina e o Caribe CEPAL (2010), "Que tipo de Estado? Que tipo de igualdade?" a conciliação entre a vida profissional e familiar baseada na redistribuição das tarefas de cuidado entre o Estado, 0 mercado e as famílias continua a ser o ponto cego das políticas públicas da América Latina e do Caribe. Existe um lapso entre as obrigações legais para com o cuidado de ambos os cônjuges em relação com seus descendentes e ascendentes e as normas, os serviços, a infraestrutura e as provisões disponíveis para sua realização. Nesta situação, as desigualdades de gênero são evidentes. Segundo Alicia Bárcena, Secretária Executiva da CEPAL, na apresentação do documento, não será possível conseguir igualdade de trabalho para as mulheres enquanto não for resolvida a carga de trabalho não remunerado e de cuidados que recai historicamente sobre elas:

A incorporação das mulheres ao mercado de trabalho em iguais condições que as dos homens requer uma análise e uma mudança estratégica da função social e simbólica estabelecida na sociedade. Isto implica, por uma parte, redistribuir a carga de trabalho não remunerada associada à reprodução e ao sustento da vida humana e, por outra, desmontar o sistema de poder que subjuga as vida livre de violência, o direito de decidir plenamente sobre a reprodução e suas condições), como na dimensão pública (a 
representação equitativa nos níveis de tomada de decisões da sociedade) (COMISSÃO ECONÔMICA PARA A AMÉRICA LATINA E 0 CARIBE - CEPAL, 2010,p. 7-8).

Desta forma, existe a necessidade de articulação entre as esferas da produção e da reprodução e do sistema de emprego e o cuidado das famílias e indivíduos. Na perspectiva da titularidade dos direitos, as políticas públicas devem garantir o acesso ao emprego, ao mesmo tempo em que provê serviços públicos para aqueles que dão e recebem cuidados. Conciliar trabalho e família é fundamental para que haja uma maior equidade entre homens e mulheres e para que a articulação entre Estado, Família e Mercado possa se dar em benefício das pessoas e da ascensão social ascendente de todos, com equidade de gênero (ALVES; MARTINE, 2010).

\section{DESIGUALDADES DE GÊNERO NOS ESPAÇOS DE PODER}

Os avanços que as mulheres brasileiras conseguiram na educação, no mercado de trabalho, nos esportes, na previdência e na sociedade como um todo ainda não se traduziram em aumentos significativos nas diversas esferas dos espaços de poder público e privado.

Porém, houve uma grande novidade no ano de 2010, pois o Brasil elegeu a primeira mulher para a Presidência da República, cargo máximo do poder público do país. Esta eleição não deixa de ser surpreendente, pois o Brasil tem uma das participações mais baixas do mundo de mulheres na Câmara Federal de deputados (ocupa $0140^{\circ}$ no ranking mundial da participação política - IPU/2010). A eleição de Dilma Rousseff colocou o Brasil entre o seleto clube de 16 países que possuem mulheres no comando máximo da política.

A presidenta Dilma, indicou nove mulheres para o ministério que tomou posse em 01/01/11. As nove mulheres no primeiro escalão, entre 37 ministros, significa um espaço de $24 \%$ para o sexo feminino, o que é um recorde histórico para os padrões brasileiros. Contudo, ficou muito abaixo da meta de um gabinete paritário que é um objetivo da campanha 50/50 (Women's Lobby 50/50 Campaign for Democracy). Já na América Latina foi aprovado, em 2007, o chamado "Consenso de Quito" que foi um acordo que o Brasil assinou na $10^{a}$ Conferência Regional sobre a Mulher da América Latina e do Caribe, ocorrida no Equador. Nesta Conferência regional foi reforçada a idéia de que a paridade de gênero é essencial para o desenvolvimento e a democracia.

Estas posições foram reafirmadas e ampliadas na $11^{\mathrm{a}}$ Conferência Regional sobre a Mulher da América Latina e do Caribe, realizada em Brasília, de 13 a 16 de julho de 2010. 0 chamado Consenso de Brasília recomendou aos países da região: 
Promover a criação de mecanismos e apoiar os que já existem para assegurar a participação político-partidária das mulheres que, além da paridade nos registros das candidaturas, assegurem a paridade nos resultados, garantam 0 acesso igualitário ao financiamento de campanhas e à propaganda eleitoral, assim como sua inserção nos espaços de decisão nas estruturas dos partidos políticos. Da mesma forma, criar mecanismos para sancionar o descumprimento das leis neste sentido (COMISSÃO ECONÔMICA PARA A AMÉRICA LATINA E 0 CARIBE - CEPAL, 2010, p. 8).

Evidentemente o Brasil está muito longe de atingir a paridade de gênero nos espaços de poder. Mas o povo brasileiro deu um passo à frente na luta por uma maior igualdade de gênero ao sufragar com $2 / 3$ do total de votos as duas mulheres candidatas em 2010 à Presidência: Dilma Rousseff com 47,7 milhões de votos, e Marina Silva com 19,6 milhões de votos.

Porém este poder de voto das mulheres não tem se traduzido em conquista de cadeiras no parlamento ou no executivo estadual e municipal. A lei de cotas que estabelece um mínimo de 30\% para as candidaturas de cada sexo não tem sido eficaz. As mulheres são cerca de 13\% nas Câmaras Municipais e das Assembléias Legislativas, 15\% no Senado, 12\% nas prefeituras e 7,2\% nos governos estaduais.

\section{CONSIDERAÇÕES FINAIS}

Os dados mostram que cresce a presença feminina em todos os aspectos da vida brasileira. As conquistas femininas aconteceram de forma gradual e progressiva, de maneira quase silenciosa, mas foram efetivas e posicionaram as mulheres para romper com o teto de vidro e atingir o empoderamento no século XXI.

0 Brasil tem passado por um processo de redução das desigualdades de gênero e de desconstrução do patriarcado. 0 patriarcado é um sistema social no qual o homem (no papel de marido ou de pai) é o ator fundamental da organização social, e exerge a autoridade sobre as mulheres, os filhos e os bens materiais e culturais. Em cada país, algumas dimensões do patriarcado predominam sobre as outras, conforme o tipo de organização social e cultural, estabelecidas historicamente. Mas em geral, o patriarcado se caracteriza por ser um sistema no qual há o predomínio dos pais e dos maridos (pater familias) sobre as mulheres e os filhos, no âmbito da família e da sociedade.

No patriarcado tradicional existe uma rigida divisão sexual do trabalho e uma grande segregação social, em geral, com as mulheres ficando confinadas ao mundo doméstico e os homens monopolizando o mundo público. 0 patriarcado, em termos materiais, possibilita ao homem o controle da propriedade e da renda da família, 0 controle do trabalho e da mobilidade da mulher e o destino dos filhos. No patriarcado 0 homem monopoliza o poder. 
Resquícios do patriarcado ainda podem ser encontrados nas relações sociais brasileiras, mas as suas bases legais e materiais estão em visível declínio. Este processo não é apenas brasileiro, mas global. Como mostrou o sociólogo Goran Therborn (2006), existe um processo de despatriarcalização da sociedade, que acontece de maneira gradual.

A quarta Conferência Mundial das Mulheres, ocorrida em Beijing, em 1995, foi mais um passo neste processo de despatriarcalização, principalmente ao definir que os direitos das mulheres são direitos humanos, buscando o empoderamento das mulheres e sua plena participação, em condições de igualdade, em todas as esferas sociais, incluindo a participação nos processos de decisão e acesso ao poder, que são fundamentais para o alcance da igualdade, desenvolvimento e o fim da violência.

0 escritor Vitor Hugo (Apud, ALVES, 2011) fez uma constatação histórica que vale para o processo de empoderamento das mulheres: "Nenhum poder na Terra pode parar uma ideia cujo tempo chegou". É neste sentido que o processo de despatriarcalização deve ser irreversível. A idéia básica do movimento de mulheres pode ser resumida em uma frase: "As mulheres devem ser tão livres quanto os homens e deve haver igualdade de oportunidade entre os sexos na família e na sociedade."

Portanto, faz parte da contemporalidade a luta pelos direitos iguais, contra a discriminação e a segregação entre os sexos, pelo reconhecimento e respeito e pela paridade e isonomia nos espaços de poder, ou seja, pela equidade de gênero. Até agora as vitórias foram parciais, mas foram conquistas acumulativas e irreversíveis. Os indicadores sociais e demográficos apresentados mostram que houve redução de algumas desigualdades de gênero e reversão de outras, mas ainda falta muito para 0 Brasil chegar a uma justa e plena situação de equidade de gênero.

\section{REFERÊNCIAS}

ALVES, JED. A transição para a Economia Verde e a Rio+20. Mercado Ético: São Paulo, 24/08/2011.

ALVES, José Eutáquio Diniz; MARTINE, George. Gênero e desenvolvimento: desafios para a integração e atualização do Cairo. In: CONGRESSO DA ALAP, Havana, 4., 2010. Anales... Disponível em: $<$ http://www.alapop.org/2009/index.php?option=com_content\&view=article\&id=621\& Itemid=339> . Acesso em: 15 dez. 2012.

ALVES, José Eutáquio Diniz; CORREA, Sônia. Igualdade e desigualdade de gênero no Brasil: um panorama preliminar, 15 anos depois do Cairo. 2009. Disponível em: 
<http://www.abep.nepo.unicamp.br/docs/outraspub/cairo15/Cairo15_3alvescorrea.pdf >. Acesso em: 15 jan. 2013.

BELTRÃO, Kaizô Iwakami; ALVES, José Eustáquio Diniz. A reversão do hiato de gênero na educação brasileira no século XX. Cadernos de Pesquisa, São Paulo, v. 39, n. 136, p. 125156, jan./abr. 2009.

BRASIL. Ministério da Saúde. Indicadores e Dados Básicos. 2010. DISPONÍVEL EM: < http://tabnet.datasus.gov.br/cgi/idb2011/a11.htm>. Acesso em: 15 dez. 2012.

BRASIL. Ministério da Saúde - Sistema de Informações sobre Mortalidade - SIM. Disponível em: <http://www2.datasus.gov.br/DATASUS/index.php?area=040701> Acesso em: 28 dez. 2011.

COMISSÃO ECONÔMICA PARA A AMÉRICA LATINA E 0 CARIBE - CEPAL. Informe de la décima Conferencia regional sobre la mujer de América Latina y el Caribe. In: CONFERENCIA REGIONAL SOBRE LA MUJER DE AMÉRICA LATINA Y EL CARIBE, 10, 2007, Quito. Anales... Disponível em: $<$ http://www.eclac.cl/mujer/noticias/noticias/3/27753/InformeFinalXConferencia.pdf>. Acesso em: 15 dez. 2012.

COMISSÃO ECONÔMICA PARA A AMÉRICA LATINA E 0 CARIBE - CEPAL. Qué tipo de estado? Que tipo de igualdade? In: CONFERÊNCIA REGIONAL SOBRE A MULHER DA AMÉRICA LATINA E DO CARIBE, 11., 2010, Brasília. Anais... Disponível em: $<$ http://www.eclac.org/publicaciones/xml/9/40129/Que_Estado_Que_igualdade.pdf>. Acesso em: 15 dez. 2012.

DUFLO, Esther. Women's empowerment and economic development. National Bureau of Economic Research Working Paper, Cambridge, n. 17702, Dec. 2011.

SCHWAB, Klaus. Global gender gap index. In: WORLD ECONOMIC FÓRUM, 2009, Davos. Disponível em: <http://www.weforum.org/reports/global-gender-gap-report-2009>. Acesso em: 15 dez. 2012.

GOLDIN, Claudia. The quiet revolution that transformed women's employment, education, and family National Bureau of Economic Research Working Paper, Cambridge, n. 11953, Jan. 2006.

INSTITUTO BRASILEIRO DE GEOGRAFIA E ESTATÍSTICA - IBGE. Pesquisa Nacional por Amostra de Domicílios. 2009. Disponível em: <http://www.ibge.gov.br/home/estatistica/populacao/trabalhoerendimento/pnad2009/> . Acesso em: 15 dez. 2012.

INSTITUTO BRASILEIRO DE GEOGRAFIA E ESTATÍSTICA - IBGE. Pesquisa Nacional por Amostra de Domicílios. 2005. Disponível em: 
<http://www.ibge.gov.br/home/estatistica/populacao/trabalhoerendimento/pnad2005/> . Acesso em: 15 dez. 2012.

INSTITUTO BRASILEIRO DE GEOGRAFIA E ESTATÍSTICA - IBGE. Censo Demográfico. Disponível em: <http://ces.ibge.gov.br/base-de-dados/metadados/ibge/censodemografico/>. Acesso em: 15 dez. 2012.

INSTITUTO BRASILEIRO DE GEOGRAFIA E ESTATÍSTICA - IBGE. Pesquisa Mensal de Emprego. 2010. Disponível em: $<$ http://www.ibge.gov.br/home/estatistica/indicadores/trabalhoerendimento/pme_nova/ >. Acesso em: 15 dez. 2012.

INTITUTO DE PESQUISA ECONÔMICA APLICADA - IPEA. Relatório Nacional de Acompanhamento - ODM. Brasília, mar. 2010

INTITUTO DE PESQUISA ECONÔMICA APLICADA - IPEA. PNAD 2009 Primeiras análises: situação da educação brasileira - avanços e problemas. Brasília, 2010. (Comunicado n ${ }^{\circ}$ 66).

ROSIN, Hanna. The end of men. Atlantic Magazine, Washington, Jul./Aug. 2010.

SOARES, Cristiane; SABÓIA, Ana Lucia. Tempo, trabalho e afazeres domésticos: um estudo com base nos dados da PNAD 2001 e 2005. Rio de Janeiro: DPE/IBGE, 2007. (Texto para discussão, 21).

THERBORN, G. Sexo e poder: a família no mundo 1900-2000. São Paulo: Contexto, 2006.

UNITED NATIONS/ESA. World population prospects: the 2010 Revision. Disponível em: $<$ http://esa.un.org/unpp>. Acesso em: 27 dez. 2011. 